\title{
La Heterocronía al abrir las ventanas
}

Heterochrony when opening the windows

\author{
Manuel Fernández Navas, Ana Yara Postigo-Fuentes ${ }^{* *}$ y Laura Insua ${ }^{* * *}$
}

Recibido: 28 de enero de 2022 Aceptado: 28 de enero de 2022 Publicado: 31 de enero de 2022

To cite this article: Fernández Navas, M., Postigo-Fuentes, A. Y. y Insua, L. (2022). La Heterocronía al abrir las ventanas. Márgenes, Revista de Educación de la Universidad de Málaga. 3(1), 193-195

DOI: http://dx.doi.org/10.24310/mgnmar.v3i1.14192

URL: https://www.youtube.com/watch?v=hKCun7TqTsc

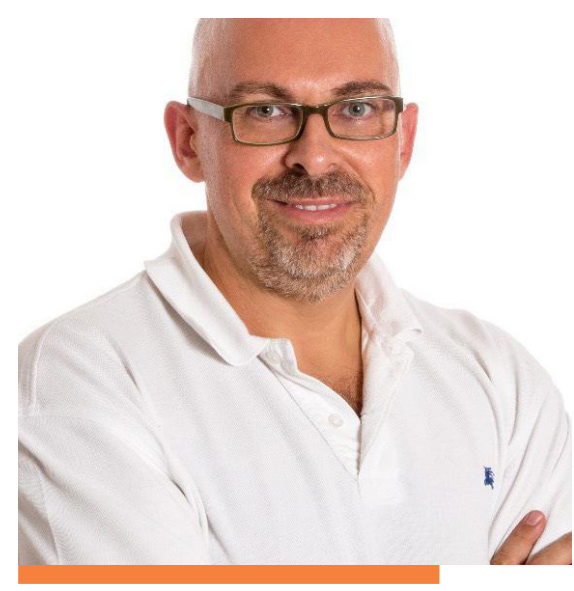

Fernando Trujillo Sáez

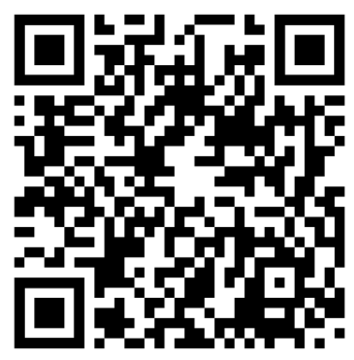

\section{RESUMEN}

Entrevistamos a Fernando Trujillo Sáez, doctor en Filología Inglesa y Profesor Titular de Universidad en el Departamento de Didáctica de la Lengua y la Literatura; quién tiene su "centro neurálgico de actividad docente” en la Facultad de Educación, Economía y Tecnología de Ceuta (Universidad de Granada) aunque, si hay algo que lo caracteriza es que está, como él mismo dice, "continuamente moviéndose”.

Palabras clave: Heterocronía; Innovación educativa; formación inicial; formación permanente

\section{ABSTRACT}

We interviewed Fernando Trujillo Sáez, doctor in English Philology and University Professor in the Department of Didactics of Language and Literature; who has his "neuralgic center of teaching activity" in the Faculty of Education, Economy and Technology of Ceuta (University of Granada) although, if there is something that characterizes him, it is that he is, as he himself says, "continually moving".

Keywords: heterochrony; educational innovation; initial training; permanent training
**Ana Yara Postigo-Fuentes 0000-0001-7965-1911 Universidad de Málaga (España) anayara@uama.es
${ }^{* * *}$ Laura Insua

Artista independiente (Cuba) Iperezinsua@gmail.com www.lauraeinsua.com 


\section{"Leo y escribo donde puedo. Hablo donde me dejan. Me gusta escuchar."}

Soy profesor de la Universidad de Granada. Enredo y crezco en Conecta13. Especialista en educación y enseñanza de idiomas. Aprendo por todos lados. Leo y escribo donde puedo. Hablo donde me dejan. Me gusta escuchar. Dirección: En movimiento

Así se define Fernando Trujillo Sáez en su web y a nosotros, que tenemos la fortuna de conocerlo personalmente, nos parece que es una definición muy ajustada a cómo es Fernando.

Su biodata podría contarse de forma breve diciendo que es doctor en Filología Inglesa y Profesor Titular de universidad en el departamento de Didáctica de la Lengua y la Literatura, que su "centro neurálgico de actividad docente" está en la Facultad de Educación, Economía y Tecnología de Ceuta (Universidad de Granada) y que, si hay algo que caracterice a Fernando, es que está, como el mismo dice, continuamente moviéndose. Sin embargo, todo esto, dejaría fuera muchas de las cosas más importantes de Fernando.

Fernando Trujillo es una de las voces educativas más autorizadas para hablar de innovación educativa de nuestro país. Con una trayectoria centrada, además, en algo muy difícil de hacer: "la coherencia entre lo que se dice y lo que se hace”.

Como gran defensor de la importancia de los vínculos entre escuela, universidad y centros de profesorado, y también como defensor de la importancia de la horizontalidad en la innovación educativa, Fernando es una de las caras más conocida de los primeros \#EABE' s. Además, se ha dejado —y se deja — la piel por ir siempre allá dónde se la ha reclamado, con el compromiso honesto de transformar los contextos en los que le dejan participar, preocupado siempre por conectar la teoría con el contexto y la práctica.

Podemos decir también que Fernando Trujillo es una de las voces más informadas en educación de nuestro país. Siempre está al tanto del último documento que se ha publicado y siempre está pensando en la próxima investigación puntera que le gustaría desarrollar. Así, ha sido el responsable de la investigación más importante sobre profesorado y COVID que se ha hecho en nuestro país durante el periodo de confinamiento. $Y$ aunque él diga en la entrevista que estas cosas son fruto de rodearse de un excelente equipo de gente, nosotros sabemos que ese es otro de sus 


\section{$\begin{array}{lllllllllllllllll} & \text { E } & N & T & R & E & V & I & S & T & A\end{array}$}

méritos: ser una excelente persona, amigo de sus amigos y reunir equipos de trabajo con ganas y dinámicas sanas para hacer las cosas.

En la entrevista hemos abordado alguno de los temas más importantes de su trayectoria: el EABE, la innovación educativa y la relación de esta con las leyes educativas, que tan de actualidad es ahora mismo. Pero también el propio Fernando nos ha mostrado conceptos como este de la heterocronía que da nombre a la entrevista y que resulta muy interesante para el análisis de algunos de los temas sobre los que charlamos. No podía faltar, por supuesto, el debate sobre la formación inicial y permanente del profesorado de la que tanto cono-

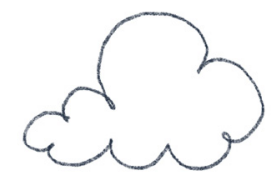
111

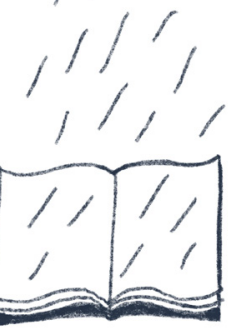
ce nuestro entrevistado. Pasando por el presente y futuro de las universidades, para finalizar con una propuesta preciosa que nos regalaba Fernando al final de la entrevista:

"Es un momento apasionante para estar en una Facultad de Educación”

Gracias, Fernando 